\title{
The Efficacy of Training Stress-Management by Cognitive- Behavioral Method in Decreasing Stress Symptoms of Women Suffering From Breast Cancer
}

\author{
Masoumeh Sattarzade Nikjeh ${ }^{1 *}$
}

\section{ABSTRACT}

Introduction: today a lot of efforts are exerted on decreasing psychological stress of women suffering from breast cancer by cognitive-behavioral training programs. Purpose: this study was done with the aim of examining efficacy of training stress-management by cognitive-behavioral method in decreasing stress symptoms of women suffering from breast cancer. Method: this study was a kind of semi-descriptive with pretest and posttest design and also following with control group in terms of applying goal and in terms of way of data collection. Statistical community is all those women that have already been identified to have breast cancer based on absolute identification of breast specialist and referred to cancer research centers of Shahid Beheshti University. From the respective statistical community, 14 women who had breast cancer were selected based on availability of choice and by various criteria and were assigned to two groups of control and experimental (each having seven people) by random assignment. The experimental group received training program through 10 sessions and the control group followed their usual plan. The research scale was 66-question version of Harry stress questionnaire. The data were analyzed by frequent measures. Findings: the results of research showed that applied intervention led to reducing the stress of women who suffered from breast cancer and this efficacy was stable over time. Conclusion: these findings represent that the stress in women having breast cancer can be reduced by training and also this method can be used as an intervention in reducing psychologically clinical symptoms of these people.

Keywords: Managing Stress, Behavioral Methodology, Stress, Women, And Breast Cancer.

Statement of the problem: psychological tensions resulting from cancer causes anxiety and depression in patients. Many concerns and depressions in individuals suffering from cancer because of losing part of the body or its function are dependence to others and losing one's role

\footnotetext{
${ }^{1}$ M.A IN Clinical Psychologist, Islamic Azad University, Science And Research Branch, Tehran, Iran *Responding Author

(C) 2016 I M Nikjeh; licensee IJIP. This is an Open Access Research distributed under the terms of the Creative Commons Attribution License (http://creativecommons.org/licenses/by/2.0), which permits unrestricted use, distribution, and reproduction in any Medium, provided the original work is properly cited.
} 


\section{The Efficacy of Training Stress-Management by Cognitive-Behavioral Method in Decreasing Stress Symptoms of Women Suffering From Breast Cancer}

in family. With regard to the fact that every change in human life is together with stress, cancer identification has also its own stress and pressure. Some of the consequences of this disease can be showing anger, wrath, depression, feeling of loneliness, absurdity, futility, jealousy, malice and so on. Some evidences show that stress plays important part in starting and developing of cancer. The results of some studies show that appearance of some kinds of cancers in children and adults is related to amount of stress brought on them. Patients who consider their disease more dangerous, more chronic and more uncontrollable become more inactive or passive, report more inability, have poorer social function and have more psychological problems. One cannot restrict treatment of a patient suffering from cancer only to clinical aspects; so it is necessary to consider these issues along clinical issues. Today the positive effect of psychological interventions is confirmed in improving process of chronic physical diseases and with daily development of the field of "health psychology", more active psychologists were used in treatment process of these diseases. Cognitive-behavioral approach is one of different approaches in psychology. This approach can help patients to reduce the negative psychological effects of their disease to least minimum level (Mohman\& Gorman,2005). Despite of significant development of medical science, the cancer still is considered as one of the most important diseases of current century and the second cause of death after cardiovascular diseases. Based on conducted studies, 80 percent of patients suffering from cancer suffer from worry and extreme stress in the early phases of their treatments. By psychotherapy one can minimize these symptoms and help patients reinforce immunity system of their bodies (Spigel, 1993). Therefore, based on presented reasons, cancer as a stressful event invites psychological reactions. Also cognitive therapy behavior proved to be useful in many chronically physical diseases. Therefore in this study the purpose of applying of this intervention therapy is to reduce stress of women suffering from breast cancer.

\section{INSTRUMENTS AND METHODS}

This study was a kind of pseudo-experimental research from aspect of data collection and from the aspect of applying goal is along with pretest and posttest and examination with control group. The community of this research was all the women who recently have been identified by specialists to suffer from breast cancer and referred to research centers of cancer in hospitals of Shahid Beheshti University in Tehran for chemotherapy. By availability sampling, 14 persons of them selected and were randomly assigned to two groups of experimental and control (with each one including seven). Criteria of entrance for the subjects were: being of age of above 30 years, female gender, lower than 1 month identification time period, tumor phase (stage2), suffered from breast cancer, lack of any sign of background of neuropsychological disease except the study cases, not having drug abuse, not having background of hospitalization because of the present disease, lack of any background of disease in the family. Criteria of exit are as follow: presence of any background of mental diseases, presence of obvious physical diseases, drug addiction, disease time span of more than one month, presence of background of disease in the 
family, suffering from other cancers other than breast cancer. Background of disease in the family of experimental group went under cognitive-behavioral treatment over ten 2-hour sessions and twice per week. In the final session, the subjects of both groups with their presence in the clinics took the posttest. After one month both groups were assessed again to follow the process. Cognitive-behavioral treatment in this research was done in groups in form of ten sessions clear instruction of each session. The content of these sessions is derived from the life skills and stress management by Anthony et al. (2007). The summary of the sessions is as follow:

First session: introduction of program, stress triggers and responses of relaxation stress

Second session: relaxation-stress and awareness: increasing awareness of physical symptoms of stress

Third session: relaxation-the relationship of thoughts and emotions (thinking power)

Fourth session: relaxation of generating effective interactive responses

Fifth session: relaxation and continuance of effective interactive responses

Sixth session: relaxation and managing anger

Seventh session: relaxation and continuance of managing anger

Eighth session: relaxation, tool-kit training

Ninth session: relaxation, continuance of tool-kit training

Tenth session: relaxation, social support and review of previous sessions

The instruments of this study with respect to field of research are demographic questionnaire and Hary's stress questionnaire. Demographic questionnaire was research made and included information like age and educations of subjects and Hary's stress questionnaire was designed by Chandran S. Harry in 2005 to assess psychological pressure in different situations of life including that of chronic patients. This scale includes 66 statements that respondent should state their answers in likert range from absolutely agree to absolutely disagree and it is designed for individual of above than 12 years old. This questionnaire was used in different studies in Iran especially for cancer patients and has appropriate reliability and validity. In this study the analysis of data resulting from questionnaires was done by different methods of descriptive and inferential statistics and by the help of SPSS software version16. The respective results were summarized and were presented in tables. Multivariate Repeated Measures Methods was applied for analyzing the data.

\section{FINDINGS}

For analyzing the data Multivariate Repeated Measures Methods was used. In this section the results of analyses of Multivariate Repeated Measures were reported for the phases of pretest, posttest and following. In reporting the results of measures, the results of Mauchly's Test of Sphericity were applied for investigating the assumption of equality of co-variances and their respective curvets. This scale is necessary for investigating assumptions of using multi-variance

(C) The International Journal of Indian Psychology, ISSN 2348-5396 (e)| ISSN: 2349-3429 (p) | 14 
analysis or multivariate repeated measures. Pillai's Trace multivariate scale, Wilks' Lambda, Hotelling's Trace and Roy's Largest Root of main and interactive effects of variance analysis and couples' comparisons were also examined.

In order to examine first and second hypotheses of the research participants' scores over filling the Hary's inventory of pretest, posttest and following phases of the research were analyzed. These hypotheses are as follow:

$\mathrm{HO}_{1}$ : training stress management by cognitive behavioral method is effective in reducing the stress of women suffering from breast cancer.

$\mathrm{HO}_{2}$ : training stress management by cognitive behavioral method has time reliability in reducing the stress of women suffering from breast cancer.

For analyzing this variable Multivariate Repeated Measures was used. In table 3-4 the results of Mauchly's Test for assessing the conditions and assumptions of applying repeated measures are presented.

Table 1: The results of Mauchly's sphericity test for assessment of conditions and assumptions of applying repeated measures.

\begin{tabular}{|l|l|l|l|l|}
\hline $\begin{array}{l}\text { Mauchly's } \\
\text { sphericity test }\end{array}$ & W Mauchly & Chi-square & Df & \\
\hline & & 10.72 & 2 & $\begin{array}{l}\text { Levels of } \\
\text { significance(Sig) }\end{array}$ \\
\hline & 0.67 & 0.005 \\
\hline
\end{tabular}

The results of table 1 represent that Mauchly's sphericity test is meaningful and significant. Since the results of this test are significant, the obtained results with assumption of stability of Sphericity should be analyzed by Greenhouse- Geisser instead of Sphericity Assumed test and Huynh- Feldt and Lower- bound tests. The results of these tests are shown in table 2.

Table 2: The results of internal effects tests of subject for experimental and control groups

\begin{tabular}{|l|l|l|l|l|l|}
\hline Test & $\begin{array}{l}\text { Sum of } \\
\text { squares }\end{array}$ & $\begin{array}{l}\text { Degree of } \\
\text { freedom }\end{array}$ & $\begin{array}{l}\text { Mean of } \\
\text { squares }\end{array}$ & F & $\begin{array}{l}\text { Levels of } \\
\text { significance }\end{array}$ \\
\hline Group & 2514.726 & 1 & 2514.726 & 8.369106 & 0.456 \\
\hline Time & 5286.067 & 1.506325 & 3509.247 & 24.14552 & 0.001 \\
\hline Time-group & 2755.356 & 1.506325 & 18.29 .19 & 12.58582 & 0.001 \\
\hline Error & 6129.911 & 42.17711 & 145.3374 & & \\
\hline
\end{tabular}

The obtained results represent that control and experimental groups are significantly different at least in one of pretes, posttest and following because the test of Greenhouse- Geisser is significant at the level of 0.001 . Also in above table the effect of factors of time and group shows

(C) The International Journal of Indian Psychology, ISSN 2348-5396 (e)| ISSN: 2349-3429 (p) | 15 
The Efficacy of Training Stress-Management by Cognitive-Behavioral Method in Decreasing Stress Symptoms of Women Suffering From Breast Cancer

that all of the people under training were improved over time. But in the factor of group meaning in pretest phase there were no difference between groups.

Table 3: the results of multivariate variance analysis for comparison of stress based on the variable of group

\begin{tabular}{|l|l|l|l|l|l|l|}
\hline $\begin{array}{l}\text { variance } \\
\text { source }\end{array}$ & test & Extent & $\begin{array}{l}\text { Assumed } \\
\text { df }\end{array}$ & $\begin{array}{l}\text { Error } \\
\text { df }\end{array}$ & F & $\begin{array}{l}\text { Levels of } \\
\text { significance }\end{array}$ \\
\hline $\begin{array}{l}\text { The effect of } \\
\text { stress } \\
\text { management }\end{array}$ & $\begin{array}{l}\text { Pillai's } \\
\text { Trace }\end{array}$ & $0 / 523745$ & 2 & 111 & $14 / 84617$ & 0.001 \\
\cline { 2 - 7 } & $\begin{array}{l}\text { Wilks' } \\
\text { Lambda }\end{array}$ & 0.476255 & 2 & 11 & $14 / 84617$ & 0.001 \\
\cline { 2 - 7 } & $\begin{array}{l}\text { Hotelling's } \\
\text { Trace }\end{array}$ & $1 / 099716$ & 2 & 11 & $14 / 84617$ & 0.001 \\
\cline { 2 - 6 } & $\begin{array}{l}\text { Roy's } \\
\text { largest root }\end{array}$ & $1 / 099716$ & 2 & 11 & $14 / 84617$ & 0.001 \\
\hline
\end{tabular}

In table 3 the results of analysis of multivariate variance of Pillai's Trace, Wilks' Lambda, Hotelling's Trace and Roy's largest root for comparison of stress based on variable of group are presented. Based on the results of this table, it can be said that groups are different in stress. This means that there is a difference at least in one of the stress tests (pretest, posttest and the following) of control and experimental group. It needs to be mentioned that the significance of multivariate variance analysis doesn't show that between which of these tests (pretest, posttest and following)in control and experimental group the difference exist. For examining these differences, binary comparison was used that their results are presented in table 4.

Table 4: binary comparisons of control and experimental group in pretest, posttest and following

\begin{tabular}{|l|l|l|l|l|l|l|}
\hline $\begin{array}{l}\text { Source of } \\
\text { changes }\end{array}$ & comparisons & $\begin{array}{l}\text { Sum of } \\
\text { squares }\end{array}$ & $\begin{array}{l}\text { Degree of } \\
\text { freedom }\end{array}$ & $\begin{array}{l}\text { Mean of } \\
\text { squares }\end{array}$ & F & $\begin{array}{l}\text { Levels of } \\
\text { significance }\end{array}$ \\
\hline time & $\begin{array}{l}\text { Pretest- } \\
\text { posttest }\end{array}$ & $7648 / 03$ & 1 & $7648 / 03$ & $27 / 13122$ & 0.001 \\
\cline { 2 - 7 } & $\begin{array}{l}\text { Posttest- } \\
\text { following }\end{array}$ & $9 / 63333$ & 1 & $9 / 63333$ & $0 / 102925$ & 0.62 \\
\hline \multirow{2}{*}{$\begin{array}{l}\text { Time- } \\
\text { group }\end{array}$} & $\begin{array}{l}\text { Pretest- } \\
\text { posttest }\end{array}$ & $3652 / 033$ & 1 & $3652 / 033$ & $12 / 9555$ & 0.001 \\
\cline { 2 - 7 } & $\begin{array}{l}\text { Posttest- } \\
\text { following }\end{array}$ & 50.7 & 1 & 50.7 & $0 / 541694$ & 0.46 \\
\hline \multirow{2}{*}{ error } & $\begin{array}{l}\text { Pretest- } \\
\text { posttest }\end{array}$ & $7892 / 933$ & 12 & $281 / 8905$ & & - \\
\cline { 2 - 7 } & $\begin{array}{l}\text { Posttest- } \\
\text { following }\end{array}$ & $2620 / 667$ & 12 & $93 / 59524$ & & - \\
\hline
\end{tabular}

(C) The International Journal of Indian Psychology, ISSN 2348-5396 (e)| ISSN: 2349-3429 (p) | 16 
As it is evident in table 4, there is a significant difference between pretest and posttest score of experimental group. This shows that training stress management by cognitive behavioral method is effective in reducing stress symptoms of women suffering from breast cancer. Also the respective table shows that there is not any significant difference between scores of posttest and following of experimental group. This means that those members of the experimental group who got lower scores in stress almost got the same scores in the following test. This finding represents that training stress management by cognitive behavioral method has reliability over time in reducing stress symptoms of women suffering from breast cancer.

\section{DISCUSSION AND CONCLUSION}

The obtained result of this study shows that training stress management by cognitive behavioral method could lead to decreasing stress symptoms of women suffering from breast cancer and even the effect of this intervention was also persistent and stable after passage of one month meaning in intervention phase. The results of this research are conforming and in line with the results of researches by Christopher, Jachob, Nihouse, Niri and Fula (2009), Chen, Jordan and Tompson(2006), Edleman and Bell (1999), Brideg et al.(1988), Darvishi Niz (1388). Moreover the result of this research is conforming with the result of research by a psychologist who was called Thomas Holmz and started his studies in first decade of 1950 and reached to this conclusion that stress is effective in severance and adversity of the cancer. The results of this research shows that cognitive behavioral method can reduce the stress of having been identified and respective treatments of cancer and also has significant role in process of treatment and adaptation of patients.

Another reason of obtaining these results is the application of cognitive behavioral methods like relaxation that was used in this study and its efficacy in the case of emotional disorders like anxiety and depression and increasing hopefulness has been proved in previous studies (Hosaka, 2000; quoted by Darvishi,1388; Yin Yung,2006; Rasman,2008).

\section{Acknowledgments}

The author appreciates all those who participated in the study and helped to facilitate the research process.

\section{Conflict of Interests}

The author declared no conflict of interests.

\section{REFERENCES}

Anthony, Michael; Ayrvnsvn, Gil; Schneiderman, Neil (2007). Practical tips of cognitivebehavioral stress management. Translated by Seyyed Javad al mohammad et al (1388). second edition. Publication of SID unit. 
The Efficacy of Training Stress-Management by Cognitive-Behavioral Method in Decreasing Stress Symptoms of Women Suffering From Breast Cancer

Badger T, Segrin C, Dorros SM, Meek P, Lopez M. Depression and Anxiety in Women With Breast Cancer and Their Partners. Nursing Research. January/February 2007; 56(1): 4453.

Bandura, A. (1999). A socio-cognetive analysis of substance abuse: a genetic perspective. Psychological Science, 10, 204-217.

Barrentt, P. G. (1999). The cost-effectiveness of methadone maintenance as a health care inversion addiction. Journal of Substance Abuse Treatment, 94, 479-480.

Belding, M. A., Iguich, M. A., Lamb, R. J., \& Terry, R. (1996). Coping strategies and continued drug use among methadone maintenance patience. American Journal of Addict Behavior, 21, 389-401.

Carver, C. S., Scheier, M. F., \& Weintrub, J. K. (1989). Assessing coping strategies: A theoretically based approach. Journal of Personality and Social Psychology, 56, 267-283.

Cassidy, L. R., \& tony, S. A. (1999). Stress, cognition, and health. New York: First published, routledge publisher.

Cassiola, J. S., Alterman, A. L., \& Rutford, M. J. (2004). The relationship of psychiatric comorbidity to treatment outcomes in methadone maintained patients. The university of Pensylvania Medical Center, 61, 271-280.

Combell, R. J. (1993). Psychiatric Dictionary. Oxford: Oxford University Press.

Endler, N. S., Parker, D. A., \& Butcher, J, N. (2003). A factor analytic study of coping style and the MMPI-2 content scales, Journal of Clinical Psychology, 59, 1049-1054.

Felton, B. J., \& Revenson, T. A. (1984). Coping with chronic illness controllability in the influence of coping strategies on psychological adjustment, Journal of Consuling and Clinical Psychology, 52, 343-353.

Fisher, L. A., \& Elias, J. W. (1996). Predicting relapse to substance abuse as a function personality dimensions, Alcohol Clinical Experimental Research, 10, 41-70.

Hanninen. V., \& Aro, H. (1996). Sex differences in coping and depression among young adults, Soc. Sci. Med, 43, 10-15.

Kaden, R. M. (2001). Behavioral and cognitive behavior therapy for alcoholism research opportunities. American Journal of Addictive Behavior. 30, 259-269.

Khantezian, E. T. (2005). Psychodynamic in substance abuse: A comprehensive text book. New York: Williams \& Willkins.

Kleinke, C. L. (1998). Coping with life challenge. Pasific, Grove: Brooks/ Cole.

Kouzekanani, K., \& Neely, M. A. (1997). Coping style of female cocaine addict. Journal of Substance Abuse, 18, 165-171.

Lazarus, R. S. (1966). Psychological stress and coping process. New York: MC Graw.

Lazarus, R. S., \& Folkman, S. (1984). Stress, appraisal and coping. New York: Springer.

Lazarus, R. S., \& Folkman, S. (1984). Stress, appraisal and coping. New York: Springer. 
The Efficacy of Training Stress-Management by Cognitive-Behavioral Method in Decreasing Stress Symptoms of Women Suffering From Breast Cancer

Lewinson, P. M., Gotlib, I. H., \& Seely, J. R. (1995). Adolescent psychopathology: IV. Specificity of psychosocial risk factors for depression and substance abuse in older adolescents. Journal of American Academy of Child and Adolescent Psychiatry, 34, 1221-1229.

Lewis, J. A., Danna, R., \& Blevins, G. A. (2002). Substance abuse conseling . California: Broks/ Cole.

Newcomb, M. D., \& Richardson. M. A. (2000). Substance use disorders. In Hersen, R. T. American (Eds). Advanced Abnormal Child Psychology, Newjersy: Lawrence Erlbaum Associated Publishers.

Pearlin, L. L., \& Scholer, C. (1978). The structure of coping, Journal of Health and Social Behavior, 19, 2-21.

Reiger, D. A. (1990). Co morbidity of mental disorders with alcohol and other drug use. Journal of American Medical Association, 964, 251-258.

How to cite this article: M Nikjeh (2016), The Efficacy of Training Stress-Management by Cognitive-Behavioral Method in Decreasing Stress Symptoms of Women Suffering From Breast Cancer, International Journal of Indian Psychology, Volume 3, Issue 4, No. 58, ISSN 2348-5396 (e), ISSN: 2349-3429 (p), DIP: 18.01.040/20160304, ISBN: 978-1-365-24976-1 